\title{
The Fragmentation of Indonesian Film Audience
}

\author{
DYNA HERLINA SUWARTO \\ BENNI SETIAWAN \\ GILANG JIWANA ADIKARA \\ Universitas Negeri Yogyakarta, Indonesia
}

\begin{abstract}
Nowadays, films can not only be watched in conventional media such as cinema, screening and television but also digital media such as streaming, download and shared archives. This study aims to determine the pattern of audience fragmentation, especially in the cinephile segments. The research employs an explorative qualitative method. The data collection methods include diaries and interviews. Informants were determined using a purposive sampling technique which includes visitors of the movie screened by the Jogja Movie Night, DIY Watching Club, and Cultural Department in July 2018. The results of this study show that, first, conventional media such as cinema and screening are still considered important because they provide a tasting guide, a space for social interaction and technical facilities. Second, attention is managed differently when dealing with conventional and new media. The focus of watching a movie can be created in different ways tailored to the viewing space. Third, film content is used as inspiration to produce films as hobbies and learning space. Also, it can be diverted in other forms such as short stories, performance scripts. Although being exposed to unlimited choices, film viewers only access the relative channels for a certain period. They need public space to interact with film fans, educate their appetite and watch satisfaction. Digital media is used to facilitate the autonomy of choosing and treating films based on their needs and desires.
\end{abstract}

Keywords: Film audience fragmentation, audience interests, consumption pattern, new media, cinephelia.

\section{INTRODUCTION}

The development of digital technology recently has led to more varied media channels. The media offers a variety of content ranging from factual to entertainment with various genres and themes. As a result, media audiences including films have many choices in accessing the desired content.

Although the landscape of digital media keeps changing, there are at least three important things that happened. First, media content and services are developing so rapidly that the amount of new material is almost unlimited. Second, old and new media continue to offer digitally integrated networks so that audiences can easily move from one cultural product to another. Third, human attention that can consume cultural products is very limited (Webster, 2011).

The variety of these media channels results in at least three important things namely fragmentation, polarization and media duality. Audience fragmentation refers to the number of media audiences distributed to various content choices (Napoli, 2003). Polarization deals with the tendency of a group of audiences to focus their attention on a type of product or media channel among many choices (Webster \& Ksiazek, 2012). Whereas, media duality is a process that combines the desires of an agent (audience) with a structure that accommodates the desire (Webster, 2005). 
The digital phenomenon highlighted in this research is fragmentation, especially film audiences. Movie viewers have the freedom to choose how to watch movies. Not only through cinema, but also the audience may watch movies through television shows, DVD/VCD, alternative cinema, film festivals, mobile services, streaming services, paid television, and others.

Audience fragmentation is not only a grouping based on conventional segmentation aspects such as demography, psychography, and geography, but also it is based on personal consumption patterns. The fragmentation of film consumers also gave rise to various habits and activities that were different from those of before (Giesbrecht, Merckelbach, van Oorsouw, \& Simeon, 2010).

Viewers can watch the same movie through various media at almost the same time. In Indonesia, the existing media for movie screenings are: paid internet services, paid television channels, DVD/VCD, alternative cinemas, film festivals, free television programs, peer sharing technology and free websites. This phenomenon leads to the fragmentation of film audiences.

One of the important film audience segments is the ordinary film lover that is also called movie lovers or cinephiles (Suwarto, 2016). They are heavyweight film viewers who are characterized by a high frequency of watching films, extensive film knowledge and critical film appreciation. Cinephile, in this digital era, has changed their experience and behaviour compared to their predecessors when the film was still a mass spectacle (Braester, 2015). The early cinephile generation only watch films, but now they are also interested in producing films.

Consuming while producing films is a phenomenon of the digital era. This is commonly referred to as prosumer and producer. The term prosumer was coined by Alfin Toffler describing the phenomenon of the roles of producers and consumers that increasingly mingle (Bruns, 2009). Producers and consumers are involved in producing information and knowledge. Prosumer who is often examined is related to news audiences, music, information, and socio-cultural basis (Sukmono, Bajari, Maryani, \& Agustin, 2019).

The discussion on fragmentation began to spark in the 2000s along with the emergence of media channel variations (Webster \& Ksiazek, 2012). The most common form of fragmentation examined is advertising, news and television audiences. The fragmentation of film audiences, especially in the cinephile segment, is a digital phenomenon that has not received sufficient attention from researchers.

Some previous studies regarding the fragmentation of film audiences include research conducted by Nikdel (2015) that aims to reveal the importance of watching films in physical space for the cinephile in the digital age. The research explains that despite the competition of various channels to watch films that are cheaper and more comfortable, cinephile still views cinema as the centre of contemporary film culture.

Meanwhile, Suwarto (2016) also examined the fragmentation of Indonesian cinema film audiences through surveys and focus group discussions. The research findings show that Indonesian film viewers are exposed to a wide choice of movie watching channels. The most popular channels consecutively are television, DVD/VCD, paid TV channels, web film festival, peer sharing, and alternative cinema. The selection of the channels is based on anticipative, evaluative, and comparative strategies.

Another study was performed by Roncallo-Dow and Arango Forero (2017) on the fragmentation of audio-visual content among Colombian adolescents. Utilizing a mixedmethod, they found that there were three forms of fragmentation namely intramedia, 
intermedia and transmedia to understand the relationship between media content producers and participatory consumers.

The three studies above discuss fragmentation only on the tendency for media choice and audience choice patterns. Therefore, this study aims to explore important dimensions of media fragmentation, namely the significance of conventional media compared to new media, attention management methods and the relationship between media choices and content preferences.

There are three perspectives for studying audience fragmentation. First, a mediacentric approach that tries to find out the total audience of various products or channels. Second, a user-centric approach that seeks to find out the media choices of each media consumer. Third, an audience-centric approach that examines fragmentation based on specific software tracking data (Webster \& Ksiazek, 2012). This research employs the second approach.

Based on the background and previous research above, research needs to be carried out to determine the pattern of fragmentation of film audiences, especially in the cinephile segments.

\section{Film: Technology and Content}

Manovich (1999) argues that a film is a form of linear narrative from beginning to end which aims to achieve cinematic duplication of realism. Reportage videos, music videos or blog videos cannot be categorized as digital films since they do not duplicate cinematic experiences that are usually obtained by the audience in the cinema.

Not only technology, but film content has also evolved so that the forms of the film have been very varied since it was first discovered now. The first film shown by the Lumiere Brothers was "Workers Leaving the Lumiere Factory" (1985) containing footage of people leaving the factory. The next film was "Train Entering The Gare De Ciotat" in the same year featured footage of train motion and people who were about to take the train. This period is usually called the era of early cinema, the film is known as snippets of pictures that are continued to recount certain events. Both of Lumiere's works can be called documentaries (Sikov, 2010).

Some years later, the film developed into a technique of storytelling through images. "Trip to the Moon" (1902) and "The Great Robbery" (1903) are films that initiate linear storytelling techniques. The story can be displayed due to the creativity of filmmakers, the development of shooting/camera movement and editing techniques. This filmmaker presents stories that can be followed by audiences: make sense in space and time along with visual enjoyment (Nowell-Smith, 1999). Since then, the narrative structure has become a distinguishing feature of films from other audio-visual media.

At the end of the silent film era, filmmakers began to appear. Viewed from the taxonomy, the genre has three functions. First, the classification of film types is based on aesthetic characteristics such as stories, backgrounds, camera techniques. Second, an economic strategy for managing production schedules. Third, the genre provides a common understanding for producers and consumers in recognizing films (Nelmes, 2012). The genre helps ease the filmmakers to produce, deliver and present certain narrative structures that are easily understood by the parties involved such as the crew, actors, investors, audiences and film marketers. Early genres that emerged were melodrama, cowboys, action/war, 
horror, comedy, animation. When voiced film technology was discovered, the genre was more varied (Nowell-Smith, 1999).

Genre is a general classification. On the other hand, there is a special categorization called authorship or known as an auteur film. This involves two important things. First, the artistic activities and certain creative expressions of a person are collaborated in such a way to produce a particular style of the film. Second, contemporary sociocultural media practices make the auteur a commodity. They are not a form of authorship romanticism but the legitimacy of the style, expression, and uniqueness of individual filmmakers (Nelmes, 2012). Auteur film creates fanatical fans of filmmakers (directors, cameramen, producers, actors, etc.). They not only like but also collect, adore and even make certain works sacred.

Other developments related to film content include discourses on world, transnational, national and local films. This distinction is usually marked by distribution and content. World cinema is usually produced by the pioneering countries of the film industry such as America and France which are then distributed extensively throughout the film through import and export companies. In this sense, there are some countries that only export films to several neighbouring countries such as India, Japan, Nigeria, Korea, and others. They are usually called transnational cinema. The contents of such films are designed in such a way that they can be accepted by different cultural backgrounds for commercial and political-cultural interests (Plate, 2016).

National films are often regarded as a representation of the nation's culture. Through national cinema, the film industry and the government have an interest in presenting the best culture for their countrymen and other nations. Therefore, cultural uniqueness is displayed as a form of supreme national culture. Usually, it is distributed nationally for diplomatic interests (Maclaird, 2013). Another form that emerged later as local films. Production, distribution and appreciation of local films are usually centred in certain cities (Shiel, 2011; Stringer, 2001). Several cities in the world such as Edinburg, Glasglow, Busan, Hong Kong became new film producers. Content locality becomes the main feature of such films. New forms of distribution such as film festivals and digital media facilitate the circulation of local films to audiences outside of their home cities.

\section{Cinema Spectatorship}

The way audiences watch films has undergone some changes that affect the viewing environment. At first, the film was shown in around show like a circus through the Kinetoscope. In that era, a simple film in the form of a moving picture was watched alone through a small hole that was reflected in the light.

When the Lumiere and brothers discovered the projector-camera, the way of watching a film underwent an important change. The film becomes a performance because the image which is usually accompanied by orchestral or piano music is displayed in opera or theatre performance spaces. The film screening team did a screening of several theatre buildings during the period. In some places, the performance space is not even permanent. The screening was carried out in a circus tent or bamboo-walled room while the audience sat on wooden or bamboo chairs. This new performance attracted the attention of the working class. Early film viewers did not demand to listen to the stories, but they found infinite interests in terms of recording and reproduction of the movements of living and inanimate objects (Nowell-Smith, 1999). 
When the film show received more attention from the wider community, some entrepreneurs established a permanent cinema called Nickelodeon in 1905. Five years later, there were approximately 10,000 Nickelodeon in America (Nowell-Smith, 1999). This screening room played films on a regular schedule even though the facilities were frequent and even fire, poor sanitation and life-threatening crowds often occurred. For decades, 1930the 1970s, cinemas became the main movie viewing place of the year despite the ups and downs of audience attention.

In 1970-1980, the house became a new entertainment space that was favored by the community due to the presence of cable/satellite television and video technology (Nelmes, 2012). When digital media began to emerge in the 1990s, films were sold and rented in the form of VCDs, DVDs and the like. The form of consumption is similar to that of video cassettes. Entering the 2000s, the internet network began to be installed at home so the distribution of films through the internet began to spread. In this context, the fragmentation of film audiences is created because there are more channels of film distribution and appreciation.

In this digital era, the role of the audience is changing. Formerly, conventional audiences were readers, listeners, viewers, spectators, and citizens, but now their roles become more complex such as users, consumers, players, producers, visitors, gifter, fans, friends, voyeur, learners and participants (Davis, 2011).

\section{Audience Fragmentation}

The explosion of channels and media content causes audience fragmentation (Webster \& Ksiazek, 2012). Audiences can no longer be segmented based on certain factors such as demographics, geography and psychographics as mass former's. The audience is no longer a mass because the combination of the three factors creates niches of fragments.

Fragmentation has changed the position of the audience as consumers and translators of symbolic messages. As consumers of messages targeted by media managers, advertisers, and public policymakers, the audience cluster in many small groups, scatter and actively determine the landscape of their media. They become more difficult to grasp and equate their opinions. Also, the viewing environment is different, therefore the way they understand the message is very different. Audiences easily move from one issue to another, there are no clear content boundaries and almost unlimited sources of information. As a result, the difference between the virtual and real-world becomes flexible, not permanent, and not linear (Livingstone, 2003).

There are three models of fragmentation, namely intramedia, intermedia and transmedia. Each will be discussed next. The concept of intermedia fragmentation was first coined by Napoli (2003) which referred to the phenomenon of the expansion of a medium to convey a variety of content. For example, cable television provides a variety of local, national and international content. There was an explosion of the content offered by a single medium. The medium is fighting over to grasp the audience attention so that the audience must be selective in choosing the content.

Intermedia fragmentation is a condition when audiences expand consumption by using various media or channels simultaneously (Napoli, 2003). For example, the audience uses an electronic slate (computer tablet) to access Twitter and Netflix. This situation creates a new viewing environment that is more than just a multitasking behaviour to understand the audience. 
Transmedia fragmentation is the most complex one because the audience not only chooses and determines their satisfaction but also create media content. User-generated content (UGC) technology allows this fragmentation to occur. Examples of this media include Wikipedia, YouTube, Quora etc. At this point, the audience can not only choose media content but also can modify the nature and purpose of the content provided by the media (RoncalloDow \& Arango-Forero, 2017).

Tammi's research (2016) on audience fragmentation shows interesting results to be observed. Although the audience is exposed to many channels and content every day, media engagement is only centred on some media. The audience allocates time and concentration to these media. The choice of media will change along with the changing of life phases and interests therefore the personal media landscape often changes. Changes in media practice are often caused by new contents and issues provided by the media.

\section{Cinephiles}

"Cinéphile" rooted in French since the 1920s represents fans of the film movement and art artists among intellectuals who consider cinema as a new art form. One of the leading cinephiles is Ricciotto Canudo who considers cinema as the seventh art. He established the Club des amis du septieme art (1919). Film club members have great enthusiasm for anything related to films such as films as arts, film critics and theories, organized writers and filmmakers, gathering and films productions. The activities of the film club had stopped during World War II (Aitken, 2001).

In the last few decades, the cinephile movement did not only occur in western countries (Europe and America) but also extended to Asian countries such as Korea, China, Indonesia, etc. New Asian cinema has its names such as film clubs (Nakajima, 2006) or cinephile communities (Li, 2013) in China, film clubs or indie film communities in Indonesia (Heeren, 2012), and cine-mania (Kim, 2006) in Korea. Beyond their name, new cinephiles find their distinctive form as a change in cinema technology and different audience facilities.

In some ways, there are similarities regarding the emergence of cinephiles in Russia and the three Asian countries, although they occurred in different periods. The first film clubs emerged in Russia in the 1960s, after the country passed from Stalinism to a softer version of totalitarianism. The same situation also occurred in South Korea right after the formation of a civil government in 1991 (Kim, 2006), in China after their economic liberalization (Nakajima, 2009) and in Indonesia after the fall of the Soeharto dictatorship regime. Because the government loses cinema regulation and censorship, cinephiles can access alternative films in terms of aesthetics, themes and politics.

In Indonesia, the cinephile community that grows after the dictatorship regime called themselves the indie film community which refers to independent films. This term, of course, creates a conflict because there are some contradictory practices associated with it. Most of this community members consist of amateur filmmakers, students (the majority) who try to produce films on a tight budget, borrow money and film equipment from friends and family, but some members have established film directors which have easy access to film equipment, funding, and even Cinema 21 theatre (Hereen, 2012).

\section{METHODOLOGY}

The design of this research is exploratorily employing a qualitative approach. Qualitative research has several characteristics. First, researchers attempt to understand human behaviour from the actor's perspective by using a phenomenological approach. Second, the 
researchers use the perspective as subjective as possible. Third, the instrument was developed temporarily, specifically, following the background of the problem and the condition of the research subjects. Fourth, the source of research validity is the depth of the data and its interpretation by the researchers. Fifth, data in the form of words, documents, observations, transcripts. Sixth, the analysis is carried out by extracting themes from research findings that are supplemented with interview excerpts, documents or description of observations. Seventh, the inductive inference is applied so that themes, images and taxonomy (classification/categorization) can be formulated (Neuman \& Robson, 2007).

Data collection and analysis techniques include a diary of media. Diaries have become a popular method in social science since the 1920s, they have been used in various fields of research, ranging from medical research to economics to record various phenomena (Tammi, 2016).

Data collection techniques through diaries aim to know the media habit of the informant. The informants filled in the forms containing questions about what media they used on that day, the duration and what content of the film they accessed.

This study employs a structured interview utilizing research instruments developed by the research team based on the analysis of the dairy notes. Based on the notes, it is revealed that some information was explored deeper in the interview. There are five topics discussed in the interview, namely media habit, channel preferences and film content, conventional media significance, attention in watching films, and prosumer. To help ease the interview process, cards that described details of the selected channels of watching films and the genre of film being watched were used.

\section{RESULTS AND DISCUSSIONS}

\section{Content and Channel Variations}

Based on the results of data analysis from the diary, the habit of watching movies is varied. Some prefer to watch long films (more than one-hour duration), while others prefer to watch short films. Several decades ago, short films did not receive significant attention in the film industry because they were considered not to get the attention of the audience. On the contrary, this research shows that short films are popular.

Movie audiences also have various genre preferences. The diary shows that a variety of genre preferences ranging from action, mystery, fantasy, drama, musical drama, experiment, romance, history, thriller, horror, biography, sports, science fiction, crime, documentaries, comedy, adventure, animation, to fiction. Many different channels of watching movies have offered film viewers to enjoy a variety of genres. Even, movie viewers consistently access certain channels to get their favourite genres.

A hobby for accessing long and short films with varied genres has influenced the number of movie titles being watched. One film title represents a single production team so that different ways of producing films are required to meet the genre and film preference. However, this study does not further explore these findings by investigating film production methods among filmmakers. Among the media that can be used to watch movies, there are at least seven media to watch films, namely, screenings, cinemas, televisions, archives (files) from friends (peer sharing), files downloaded from the websites, websites streaming and files from internet cafes. The first three media are models of accessing conventional films that have been popular for decades. Whereas four other media are a relatively new form of film distribution. At present, the entire film archive that circulates both in conventional media and 
new media is in the form of digital. Digital archives are very easy to store, upload, download, and copy so movies can be easily spread widely through these digital archives. The quality of digital archives varies depending on the storage media and distribution. Archives on television, theatres and screenings are usually large enough to be projected on the big screen. While archives circulating on websites, cell phones, personal computers are usually not good enough to be projected onto the big screen. This affects the quality of the image and sound displayed in the archive, thus it creates a different viewing experience.

Archives obtained from the website can be watched directly or downloaded first. The website to download movies includes Torrentpiratesbay, dunia21.net, drakorindofilms.net, Indoxxi.com, samehadaku.tv, dramafever, LK21, youtube. Some similar websites like Drakorindofilms.net, Indoxxi.com, LK21, YouTube are used to watch movies streaming. Other websites include Iflix, Vidsee.com, nontongo.com, andronymous77, kangfalah @idws, murjani.blogspot, viu.com, anoboy, HOOQ, otakustream, ganool, filmapik.com, shortoftheweek.com. People also go to the cinema to watch a movie even though the frequency is much less than a visit to the website.

\section{Media Habit}

The most widely used media is a website for watching and downloading movies. Next is the archive from friends and screenings. The most unpopular media include internet cafe and television archives.

Website streaming is often used to get films due to its ease of access, decent picture quality, genre variations, low cost and flexibility to determine films. According to Achmat "for websites, the access is easy and the response and regeneration of the film are fast". Also Johanis "we have the freedom to choose if we use the website"

In addition to watching movies directly, the website is also a place to download movies. Downloading movies is cheaper than streaming because viewers spend less quota. The benefit of downloading movies compared to streaming is that the same movie can be watched many times, according to Akmala. Viewers can choose the right time to watch a movie, in contrast to screenings and the cinema that must follow a schedule determined by other people.

Good internet infrastructure is the reason movie viewers in accessing and downloading movies on the website. They usually do these activities on campus and at home/boarding house. They are connected to wifi so that they can watch movies. The cost is relatively cheap compared to go to the cinema and watch film screenings. They only need to pay a subscription fee that is often included in the house or boarding bill. If they are connected to wifi on campus, they don't even have to pay any fee.

Archives from friends and screenings are also channels, though not the main channel, for getting important films. The audience usually gets a movie from a friend due to a friend's recommendation. They usually have the same taste or the friend is considered to have a good/current movie taste. Moreover, screening is also considered an important channel because people like to interact with fellow film lovers and filmmakers. The manager of the screening program is also considered to have a good film preference so that it is suitable as a reference. Another reason is that films shown on screenings are rarely found on websites or theatres. Such a film is considered unique by informants so it is worth watching. Screening is a place to increase knowledge about a variety of topics, sharpen aesthetic tastes and provide socialization spaces. 
Although film viewers feel that they have the best movie viewing experience in the cinema, this channel is no longer considered the main one. Viewers visit the cinema 1-2 times a month, some even quite rarely go to the cinema. The main problem is the cost, so they think twice when they want to watch films in the cinema. Films that require a special atmosphere such as sound and complexity of the images are watched in the cinema. Another factor that enhance viewers to watch films in the cinema is social encouragement from friends.

Television is not an interesting channel for film viewers. According to them, television only shows old films that have been watched. In addition, advertisements that intersperse scenes or appear during movies reduce viewing comfort. The time required to watch a film on television is longer than watching it on a website through streaming or archives, even though the picture quality is relatively the same.

\section{Channel and Genre Preferences}

Horror and action movie fans tend to choose cinema as the main alternative due to better sound and picture sensations. But, some get the film archive so that it can be watched many times.

It is interesting to note, most of them claim that film viewers could not bear to watch Indonesian films on illegal websites because they felt guilty. Therefore, film viewers try to watch films in theatres or screenings if they are interested in watching Indonesian films. The two channels are spaces for the appreciation of domestic works. But, cinema often becomes the destination of watching the latest Indonesian films because film screenings are not routinely held.

The audience chooses a new movie and then determines the channel, but some choose the channel and then try to find the right movie with the mood they are in or want to feel. The targeted films are usually investigated mainly through film forums on social media and friend's recommendations. Then, they search for films on various channels. The choice of the main channel considers the principle of ease and flexibility of time.

I prioritize the content first, then the channel. As I said earlier, if the content requires a good atmosphere, then I will choose a channel that supports it (Ayunita).

I usually consider the genre first, but it doesn't matter if the media offer the genre that I like. The emphasis is on the media (Riyanti).

\section{Significance of Conventional Media}

Digital media offers convenience to access films but most viewers argue that conventional media such as television, screenings and cinemas are still important for distributing films. The cinema offers the best viewing experience because the facilities and atmosphere make the audience enjoy the film with ease.

For example, the cinema offers supporting facilities such as better sound and little noise. When using digital media, for example using a headset, the effect is not good. Therefore, it feels different when watching a movie in theatres (Andara). 
However, some argue that conventional media and new media can facilitate watching films. There is no difference regarding the viewing experience that is created because they try to create the right atmosphere for watching movies in their personal space. Movie viewers who don't consider the channel usually do a few tricks to make the viewing experience like locking the door, turning off the room lights, wearing a head seat, choosing a wide-screen computer and so on. Solitude becomes a unique source of enjoyment of watching movies compared to watching movies in theatres and screenings.

\section{Attention Management}

Film screenings and cinema offer more or less the same viewing experience but the situation is somewhat different from the experience of watching movies using computers, laptops, cellphones and television. Technical facilities in the cinema allow viewers to enjoy the film's images and sound optimally, rules must be followed by the audience so that an atmosphere can be created. Film screenings usually try to follow the atmosphere in the cinema but the technical quality is lower.

Meanwhile, digital media offers different ways of managing attention from cinema and screenings. Through digital media, film viewers have the power to control situations such as speeding up, slowing down, and repeating. With this feature, the audience feels that they can focus more on watching movies. On the contrary, television creates a lot of distraction because of advertising and television placement space. Due to this reason, television becomes the last choice for watching movies.

The audience feels that the situation in the cinema helps them focus on watching the film because the atmosphere is created. But the situation has a weakness, if they fail to understand the film at some point, they cannot repeat it. For that reason, film-goers must be prepared for the viewing situation by gathering information related to the film before watching it so they can anticipate the experience.

Using traditional media (cinema and screenings) enable us to be more focused on watching a film because the atmosphere prevents us from leaving even a second. But, if we use digital media, we can still focus on what we like until the end, or we can pause and repeat as we like (Cessa).

The audience often wants to understand the film as optimal as possible, some of them even observe the details of certain scenes such as camera angles, actor expressions and aesthetics. It can be done through digital media so that the audience feel more focused on watching a film. The satisfaction of watching a film is not determined based on the experience following the film's flow but is based on the ability to follow the film's details. According to Ahmad "when there is a dialogue that needs extra understanding, I pause the movie for a moment". Also, Andara argued that:

In my opinion, it is more satisfying to watch a movie on the website and get it from peer sharing because we have the freedom to choose. Moreover, we can understand better, pause, repeat, advance as we like (Andara).

Compared to other media, television is the least desirable. In general, the audience is no longer interested in watching television because the program is considered boring. They just sit in front of the television to approach family members or friends who are watching 
television as media for socialization. If they want to watch movies, television is not the right media due to the quality of the picture, sound and distraction from advertisements.

\section{The Role of Prosumer}

The film is a media text that can display a variety of new information and knowledge. In addition, the film brings certain moods and aesthetics. Those become the attraction of the film according to the informants. As their passion for watching movies arises, the desire to produce their films also increases. Film viewers then make this into a hobby and even make it a career in the present or future.

Films that have been produced are usually distributed to film festivals, film competitions and screenings for their friends. Film viewers feel their satisfaction when they can produce films. So that the produced film meet the expectations, they look for some films as references, imitate and modify according to their technical abilities.

I make a film. I began making a film when I like writing and reviewing films that I've watched. It does not give great benefits if I just like watching a film but I can't produce it. I usually write things more, but technically I am less capable (Yustisia, 21).

Some inspirations obtained from films are not realized in the form of films. Some informants use stories, backgrounds, rhetoric, aesthetics obtained from films to compile short stories, film scripts and comedy scripts. Currently, they are quite satisfied with their work and there is no desire to make it as a film.

I like standup comedy. I like watching comedy films because I want to pay attention to the punch lines they make, what punch lines can make people laugh (Billy, 20).

Based on the data above, the audience accesses the cinema through three main devices: cinema, screenings, computer/laptop. Each device provides a relatively different viewing experience so that they adjust their behaviour to the nature of these media.

Using computers, they can access a variety of almost unlimited channels. Although the audience is exposed to many channels and content every day, media engagement is usually only focused on a few media (Tammi, 2016). In this study, the are only 21 digital media channels that are commonly accessed. The main consideration is convenience and cost. A cinephile who watches films using digital devices is not satisfied with one-time watching. If the viewers like a certain movie, they will save the file to watch it over and over. They are building audience experience in private spaces as collectors and digital interactive users. This group find their togetherness through cyberspace (Elsaesser, 2012). So, users who have a favourite genre tend to only visit the same channel on the internet.

Although digital media is considered the cheapest and easiest, conventional media such as cinema and screenings are still used for different reasons. Cinema is considered to provide the best technical facilities and the lowest distraction. Because the cost is high, the audience wants to get optimal satisfaction by watching a movie in the cinema. They anticipate the experience by collecting adequate information before selecting films. If there is a new film that has a favourite genre or filmmaker (director, production house, actor), they will 
prioritize watching it in the cinema (Suwarto, 2016). However cinema has weaknesses, film viewers must follow the existing schedule and it does not provide space for discussion or rewatching if they don't understand the content.

The screening was chosen because it offers social interaction with fellow film lovers and filmmakers as well as discussion forums that can increase knowledge related to the film. Cinephile is fully aware that films in screenings are very different from films in cinemas and websites. They are eagerly awaiting the surprise. However, because information about film screening activities is often spread even hard to find, this fondness is not realized. The fondness for the screening of this film is similar to the behaviour of classical cinephile that considers that watching films in public spaces gives rise to certain sacred feelings (Elsaesser, 2005).

The choice of using digital archives from websites or shared digital archives is a manifestation of the active process of selecting the intended content to satisfy desires. This behaviour is in line with theories of uses and gratification (Adoni \& Nossek, 2001). To be able to shape certain tastes, film viewers need to 'educate' their tastes by gathering intensive information from various sources, especially websites, social media, and friends who understand films. In short, they need to have film literacy skills before they can choose content and find the right channel. Due to cost reasons, most of them access illegal channels. Based on film literacy, cinephile builds taste autonomy mediated by digital media sources (Napoli, 2011).

\section{CONCLUSION}

Based on the data and discussion above, the conclusions are as follows. The results of this study show, first, conventional media such as cinema and screening are still considered important because they provide a tasting guide, a space for social interaction and technical facilities. Second, attention is managed differently when dealing with conventional and new media. The focus of watching a movie can be created in different ways tailored to the viewing space. Third, film content is used as inspiration to produce films as hobbies and learning space. In addition, it can be diverted in other forms such as short stories, performance scripts. Although being exposed to unlimited choices, film viewers only access the relative channels for a certain period. They need public space to interact with film fans, educate their appetite and watch satisfaction. Digital media is used to facilitate the autonomy of choosing and treating films based on their needs and desires.

\section{BIODATA}

Dyna Herlina Suwarto is assistant professor at department of communication studies Faculty of Social Science Universitas Negeri Yogyakarta. Email: dynaherlina@uny.ac.id

Benni Setiawan is an assistant professor at the department of communication studies Faculty of Social Science Universitas Negeri Yogyakarta. Email: bennisetiawan@uny.ac.id

Gilang Jiwana Adikara is lecturer at department of communication studies Faculty of Social Science Universitas Negeri Yogyakarta. Email: gilang.ja@uny.ac.id 


\section{REFERENCES}

Adoni, H., \& Nossek, H. (2001). The new media consumers: Media convergence and the displacement effect. Communications, 26(1), 59-84.

Aitken, I. (2001). European film theory and cinema: A critical introduction. Indiana University Press.

Braester, Y. (2015). The spectral return of cinema: Globalization and cinephilia in contemporary Chinese film. Cinema Journal, 55(1), 29-51.

Bruns, A. (2009) From prosumer to producer: Understanding user-led content creation [conference paper]. Transforming Audiences 2009, 3-4 Sep, London.

Davis, C. H., \& Michelle, C. (2011). Q methodology in audience research: Bridging the qualitative/quantitative 'divide'. Participations: Journal of Audience and Reception Studies, 8(2), 559-593.

Elsaesser, T. (2005). Cinephilia or the uses of disenchantment. Cinephilia: movies, love and memory, 27-43.

Elsaesser, T. (2012). The persistence of Hollywood: From cinephile moments to blockbuster memories. Routledge.

Giesbrecht, T., Merckelbach, H., van Oorsouw, K., \& Simeon, D. (2010). Skin conductance and memory fragmentation after exposure to an emotional film clip in depersonalization disorder. Psychiatry Research, 177(3), 342-349.

Heeren, K. V. (2012). Contemporary Indonesian film; Spirits of reform and ghosts from the past (p. 239). Brill.

Kim, S. (2006). From cine-mania to blockbusters and trans-cinema: Reflections on recent South Korean cinema. Theorising National Cinema, London: BFI, 186-201.

Li, J. (2013). Piracy cultures| From "D-Buffs" to the "D-Generation": Piracy, cinema, and an alternative public sphere in urban China. International Journal of Communication, 6.

Manovich, L. (1999). What is digital cinema? In P. Lunenfeld (Ed.), The digital dialectic: new essays on new media (pp. 172-192). Cambridge, MA: MIT Press.

Nakajima, S. (2006). Film clubs in Beijing: The cultural consumption of Chinese independent films. In Pickowicz, P. G., \& Zhang, Y. (Eds.) From underground to independent: Alternative Film Culture in Contemporary China (pp. 161-187). Rowman \& Littlefield.

Napoli, P. M. (2003). Audience Economics: Media institutions and the audience. Columbia University Press.

Nelmes, J. (Ed.). (2012). Introduction to film studies. Routledge.

Neuman, W. L., \& Robson, K. (2007). Basics of social research: Qualitative and quantitative approaches. Power, 48, 48.

Nikdel, E. W. (2015). Re-centering the cinema experience in a multi-platform, digital age. Networking Knowledge: Journal of the MeCCSA Postgraduate Network, 8(5), 119.

Nowell-Smith, G. (1999). The Oxford history of world cinema. Oxford University Press.

Plate, S. (Ed.). (2016). Representing religion in world cinema: filmmaking, mythmaking, culture-making. Springer.

Roncallo-Dow, S., \& Arango-Forero, G. (2017). Introducing three dimensions of audience fragmentation. Signo y Pensamiento, 36(70), 74-90.

Shiel, M. (2011). Cinema and the city in history and theory. In M. Shiel \& T. Fitzmaurice (Eds.), Cinema and the City: Film and urban societies in a global context (pp. 1-18). WileyBlackwell. 
Sikov, E. (2009). Film studies: An introduction. Columbia University Press.

Stringer, J. (2001). Global cities and the international film festival economy. Cinema and the city: Film and urban societies in a global context, 134-144.

Sukmono, F. G., Bajari, A. B., Maryani, E., \& Agustin, H. (2019). The characteristics of Indonesian multicultural movie audiences in post-1998: A study of the Yogyakarta movie community. Jurnal Komunikasi: Malaysian Journal of Communication, 35(3), 108-124.

Suwarto, D. H. (2016). Analisis segmentasi penonton bioskop Yogyakarta. Informasi, 46(2), 215-222.

Tammi, R. (2016). Engaging with media in the fragmented media environment: Using multiple methods to discover elements of media engagement [Doctoral dissertation, Aalto University, Helsinki].

Webster, J. G. (2005). Beneath the veneer of fragmentation: Television audience polarization in a multichannel world. Journal of Communication, 55(2), 366-382.

Webster, J. G. (2011). The duality of media: A structurational theory of public attention. Communication Theory, 21(1), 43-66.

Webster, J. G., \& Ksiazek, T. B. (2012). The dynamics of audience fragmentation: Public attention in an age of digital media. Journal of communication, 62(1), 39-56. 